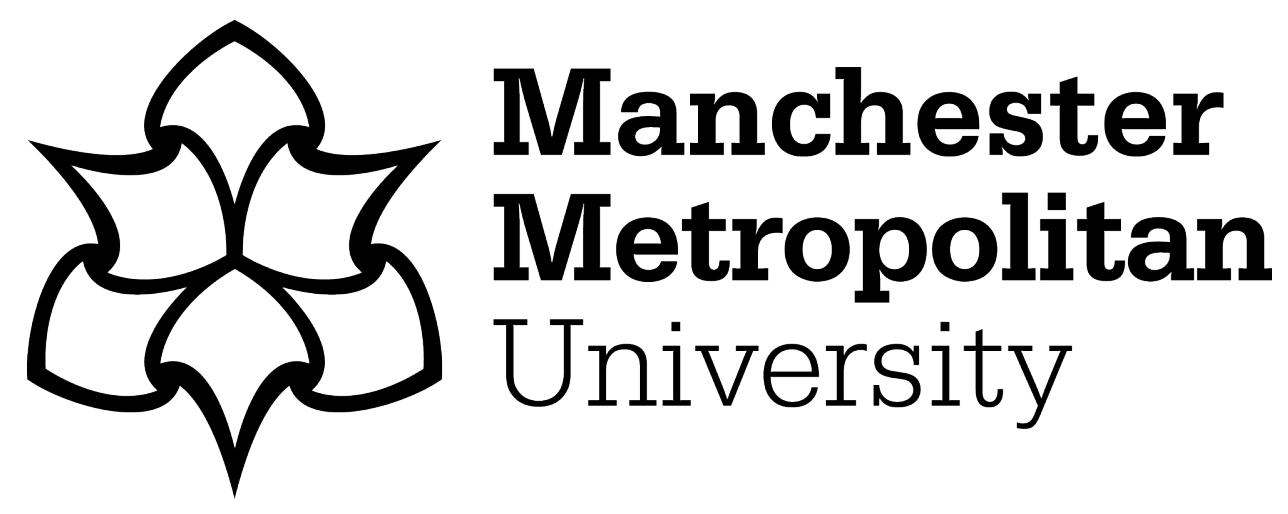

Gray, P ORCID logoORCID: https://orcid.org/0000-0002-1546-9333 and Seddon, T (2005) Prevention work with children disaffected from school: Findings from the evaluation of two innovative community-based projects. Health Education, 105 (1). pp. 62-72. ISSN 0965-4283

Downloaded from: https://e-space.mmu.ac.uk/617310/

Publisher: Emerald

DOI: https://doi.org/10.1108/09654280510572312

Please cite the published version 
Received December 2003 Accepted April 2004

\section{Prevention work with children disaffected from school}

\section{Findings from the evaluation of two innovative community-based projects}

\author{
Paul Gray \\ Department of Criminology, Keele University, Keele, UK \\ Toby Seddon \\ Centre for Criminal Justice Studies, School of Law, University of Leeds, Leeds, UK
}

\begin{abstract}
Purpose - To report on findings from the evaluation of two innovative community-based prevention projects in the UK targeted at children disaffected from school, one involving football the other horticulture. Design/methodology/approach - Qualitative inquiry focusing on three areas: "theories of change" underpinning the projects; referral and operational processes; inter-agency partnerships. Main methods were: an interactive event for 50 practitioners; semi-structured interviews with project staff, project participants and other stakeholders; review of project documentation; observations.

Findings - Both the projects evaluated had clear and plausible "theories of change". Referral processes were effective. Strong variations in "dosage" and length of project involvement appeared to be linked to differences in the effectiveness of the two projects.

Research limitations/implications - The principal limitation to the research was the lack of case monitoring and outcome data that prevented any quantitative assessment of the projects. Further research is needed to establish the long-term impact of this kind of targeted prevention work.

Practical implications - Prevention work targeted at children disaffected from school needs to be underpinned by clear "theories of change". Effective work requires good relationships with referring schools, the delivery of multi-faceted interventions and interventions to be of an adequate length.

Originality/value - The focus on "theories of change" or mechanisms is an original contribution to the prevention literature. The paper will be valuable for those working in drug action teams and local authorities in planning prevention work for young people. The two projects were highly innovative in involving pupils in two very different activities - football and horticulture.
\end{abstract}

Keywords Schools, Drugs, Youth, Communities, Peer mentoring, United Kingdom

Paper type Research paper

\section{Introduction}

Research background

The problem of truancy and exclusion from school has risen up the political agenda in recent years. This is partly because of a sharp rise in levels of recorded permanent

Angie Heal, a Senior Research Officer at Nacro at the time of the research, carried out most of the fieldwork for these two projects and conducted the initial project-level analysis. Ruth Francis did some of the interviews with young people and also provided administrative support. Penny Fraser and Toby Seddon jointly managed the research that was funded by the Department of Health, the Home Office and the Manchester Salford Trafford Health Action Zone. Thanks to all the research participants for their time and co-operation. We are also grateful for the support throughout the work of the Evaluation Reference Group set up by the Health Action Zone. 
exclusions that more than quadrupled during the 1990s. The impact of this on educational attainment has, of course, been a major concern for policy-makers but there is also a wider anxiety about the issue. Emerging research evidence suggests that there may be links between truancy/exclusion and other social problems, such as, drug use (Lloyd, 1998; Goulden and Sondhi, 2001) and offending and anti-social behaviour (Graham and Bowling, 1995; MORI, 2000; Flood-Page et al., 2000). As the Audit Commission (1996 p. 66) put it in their landmark report on youth crime and youth justice:

School truancy and exclusion are both key indicators of trouble to come.

From a health perspective, the apparent link between school truancy/exclusion and vulnerability to developing drug problems (Goulden and Sondhi, 2001) is significant. Additionally, there is also evidence showing an association between truancy/exclusion and socio-economic deprivation (Social Exclusion Unit, 1998) and the latter has been found to be a key driver of health inequalities (Townsend, 1998). The implications for health improvement are twofold. First, in general terms, reducing levels of truancy/ exclusion may by itself have some public health benefits. Central government initiatives to address school exclusion, truancy and pupil support are likely to be helpful in this respect. Second, early intervention or prevention work targeted at children disaffected from school may be an important site for preventing problem drug use and reducing health inequalities (and, more widely, for preventing offending and anti-social behaviour). This paper reports findings from the evaluation of two such targeted prevention projects.

\section{Background to the projects}

The creation of Health Action Zones (HAZs) formed a central part of New Labour health policy in the late 1990s. HAZs were also part of a wider family of area-based regeneration initiatives (e.g. New Deal for Communities) aimed at tackling social exclusion and modernising public services. They were intended to act as "trailblazers" in developing innovative solutions to reducing health inequalities, leading the way for other areas to follow. It was in this context of tackling health inequalities and social exclusion through innovation and modernisation, that the Department of Health and the Home Office set up a programme to provide, through HAZs, pump-priming funding for innovative drug prevention projects targeted at "vulnerable" young people. One of the "vulnerable" groups identified was truants and school excludees.

In 2001, Nacro was commissioned to evaluate seven of these prevention projects being run within the Manchester Salford Trafford HAZ. This article focuses on two of the projects: the Manchester City Kick It Football Project and the Salford Anti-Rust Gardening Mentoring Project. Both were targeted at disaffected secondary school children in "trouble" at school, truanting and/or at risk of exclusion. The article will explore in turn how these two projects worked, assess their prevention potential and set out recommendations for the future development of this kind of work.

\section{Methods}

The initial set-up phase of the evaluation consisted of a number of tasks. Available documentation about the projects was collected and initial visits arranged. Visits were used to introduce the evaluation and its requirements, to find out more about the 
projects and to scope their existing data collection practices. During this period, the research instruments were developed. A literature review was also conducted and some information gathered about relevant projects in other areas.

It became apparent during the scoping of existing data collection practices that neither project had any case monitoring systems in place and that it was not feasible, for a variety of reasons, for this to be remedied during the life of the evaluation. This meant we were unable to collect quantitative data on participants and on outcomes. It was decided therefore to focus the evaluation on a qualitative enquiry in three areas: the mechanisms or "theories of change" underpinning the projects; the referral and operational processes of the projects; and the inter-agency partnerships involved.

For the first area, we began by organising an interactive learning event with practitioners that was designed as a means of teasing out theories and hypotheses about how different prevention techniques work, who they work best with and in which contexts or settings. The event involved around 50 people from the HAZ area engaged in prevention work with young people. All discussion sessions at the event were tape-recorded and we then used this material to draw up a "matrix" of prevention techniques and mechanisms (for more details on this matrix, see Fraser and Seddon, 2003). This matrix then fed in to the design of interview schedules for project workers and project participants and also informed subsequent data analysis. Interviews with project participants primarily focused on exploring project "mechanisms" but also covered some issues concerning referral and operational processes.

For the second and third areas, we conducted a series of interviews with project managers, workers and volunteers and with representatives from partner agencies (as noted above, the project participant interviews also touched on the second area). We also analysed project documentation and carried out observations of the projects in operation. In addition, in the last phase of data collection, a series of interviews with $\mathrm{HAZ}$ staff and representatives from key strategic partner agencies (such as drug action teams and the drug prevention advisory service regional adviser) were conducted. These interviews explored more strategic issues, including the role of the HAZ and its relation to the three drug action teams.

Analysis of the interview data was undertaken using NUD*IST5, a software package designed for the analysis of qualitative data. The basic structure of the coding tree was derived from the semi-structured interview schedules but additional nodes were added during the coding and analysis process as concepts were developed directly from the data, using a "grounded theory" approach (Glaser and Strauss, 1967).

\section{Findings}

Manchester City Kick It football project

Project model. The Kick It mentoring project was designed as a supplement to an existing drug education programme. This existing programme, initially launched in 1996, was established by football in the community at Manchester City Football Club. It was based on promoting football as a healthy diversionary activity. Training and coaching sessions were coupled with classroom-based drug education sessions delivered by the project worker. The target group was children in their final year of primary school.

To supplement this successful programme, it was decided to use HAZ funding to develop a targeted mentoring component for secondary school children. The idea was 
for participating schools to refer children who were starting to get into "trouble" or to truant and who already had an allocated education mentor. Each pupil referred to the project was given a training session at the football club where the project, and what it does in primary schools, was explained to them. The pupils then accompanied the Kick It project workers on their visits to primary schools and helped to deliver the drug education sessions. After an agreed attendance, the pupils received certificates, and in some cases tickets for football matches.

Mechanisms for change. The Kick It project was intended to have a preventative impact through four principal mechanisms:

(1) raising the self-esteem, confidence and enthusiasm of participants;

(2) providing a positive role model in the project co-ordinator (a former footballer at the club who was originally from the local area);

(3) communicating messages about healthy living and the value of physical activity through the football activities; and

(4) communicating drug education messages through participation in the primary school sessions.

As an additional side-benefit, the involvement of older children in the primary school drug education sessions was intended to enhance their credibility and effectiveness by, in effect, introducing a peer-education dimension to the programme. As a model, the Kick It mentoring component was an economical and imaginative way of adding to an existing successful programme.

Targeting and referrals. As described above, the project was targeted at children in "trouble" at school. Initially the project attempted to work with young people from pupil referral units. However, it was found that they were often unreliable and did not attend sessions. Consequently, the project felt that these pupils were not appropriate young people for them to work with and this was not attempted again.

After this difficult start, the project worked with pupils from a number of secondary schools in Manchester. The young people referred were those who had usually already been identified as having some problems in school and were already working with education mentors. They were disaffected, on the verge of getting into or already in some trouble, and turned off by the education system. However, they were also willing to respond to instructions, interested in attending the project, and had a sufficient degree of understanding of what was required for their participation. An understanding of appropriate referrals had clearly been communicated to referring schools:

Decisions about referrals are made with consultation to the year head. We decided which pupils were reliable enough to see the scheme through but were disaffected with school, those who would get the most out of it [...] I decided not to send those with huge behavioural problems because that wouldn't help the project (head of PHSE).

I think the people who are most suitable for referral to the project are the pupils who are more committed to their own futures. They would see it through better (senior learning mentor).

Partnerships. The principal partnerships were between Kick It and referring schools. The key contact was between the project worker and the head of PHSE in each school. 
These relationships were generally felt to work well, although some school staff noted that more regular and structured feedback about children's progress would be helpful. There were clear potential mutual benefits of a good working relationship that undoubtedly helped to motivate both parties: for schools, improvements in behaviour and attendance; for Kick It, regular and appropriate referrals. From the schools' side, it was felt by some of those interviewed that the project had too low a profile within the community and that it could benefit from linking to other community arts and education networks.

Kick It also referred some young people on to other agencies where appropriate. For example, two were referred to Lifeline, a local community drug service provider, as it was felt they required some more in-depth one-to-one work focused on drug issues. The Kick It project co-ordinator attended local drug worker networks which was useful in terms of keeping him informed of available local resources.

Effectiveness. The project potentially had a lot to offer young people and as noted above there were some clear mechanisms through which positive change might be achieved. The interview data suggested some important limitations on the project's effectiveness as well as some areas of potential.

In terms of limitations, the young people interviewed said they enjoyed the mentoring programme but felt that the relatively short period of participation (in practice, only two or three sessions) meant that it was more of a "taster" rather than an intervention likely to lead to any sustained change. The research literature suggests that mentoring interventions need to last at least a year for sustainable gains to be achieved and there is some debate about whether even this is long enough (Tarling et al., 2001; St James-Roberts and Singh, 2001). No needs assessments or any tailoring of the programme to individual needs took place either.

Despite this, all the project staff interviewed felt that the young people had generally benefited in some way from attending the Kick It mentoring programme but this was restricted primarily to perceived increases in confidence and self-esteem.

Overall, the evaluation suggested that the mentoring component of Kick It had enormous potential but, at the time of the research, this had not been realised. A longer-term, more intensive and tailored programme might well achieve some successful prevention outcomes as the project model was a theoretically promising one.

\section{Salford Anti-Rust Gardening mentoring project}

Project model. The Anti-Rust project started out at a council allotments site in the mid-1990s and grew out of the activities of volunteers who had allotments there. More recently, it had re-located to a site at a local park. The project engaged a small group of young people aged 13-15 in horticultural activities and learning for three days per week during term-times. On the other two days the pupils were expected to attend school. A key part of the project was that participants had to attend both school and the project in order to continue with Anti-Rust and attendance was monitored very closely. During the two days in school, there was a particular focus on English and Maths. Participation in the project lasted for up to two academic years for each pupil.

The project worked closely with one particular school that referred pupils to them as part of their alternative curriculum. The pupils were initially identified by teachers and referred to the project via the head teacher, who had a close involvement with Anti-Rust. Following referral, there would be an initial meeting between the pupil, their 
parents/carers, their teacher and a member of staff from the project. Initial meetings would typically last at least one hour and would cover what participants were expecting, who they would work with, the structure and times of the training, what training the project provided and what was expected from participants in terms of attendance, performance and commitment. At these meetings, it would be clearly spelt out that it could be hard work, in varying weather conditions, and that it was not an easy option or a way to escape school three days a week. In view of the length of time pupils attended the project, the full agreement of parents/carers was felt to be vital.

Work on the project was planned around the growing season. The pupils were expected to be involved in all aspects of producing vegetables, from preparing the ground to harvesting crops. They were also expected to produce short reports, and help would be given with this if they had literacy problems. Project work had no specific focus on drugs at all and, indeed, staff were keen that it should not be described as a "drug prevention" project for fear that this might put off some prospective pupils or their parents or carers.

Mechanisms for change. The Anti-Rust project was intended to have a preventative impact through six principal mechanisms:

(1) Supporting pupils in continuing to attend school.

(2) Providing long-term adult mentoring relationships with the project workers.

(3) Teaching practical horticultural skills.

(4) Providing work experience.

(5) Communicating healthy eating messages and increasing home consumption of fresh vegetables.

(6) Providing constructive alternative activities to involvement in drugs, crime or anti-social behaviour.

Targeting and referrals. During the HAZ funding period, the project received ten referrals, all of whom were boys. Referrals were targeted mainly at those with difficulties at school. These ranged from learning difficulties to behavioural, social and emotional difficulties. Not all suitable or eligible pupils were referred as the project was limited in the number of places it could offer. The project did not turn down any referrals made by the school. Suitable referrals needed to have a certain level of maturity to be able to respond to clear, structured guidance and be capable of following the project through to the end. If parents/carers strongly objected to the referral then that would also make it unsuitable as their commitment was viewed as essential.

Partnerships. The project operated as a partnership between the referring school, Anti-Rust, the pupils and their parents/carers. Interviews indicated that all these relationships worked extremely well. For example, the head teacher from the referring school stated:

There's very open communication. We are working together. Very good partnership [...]

I think it has been a tremendous success.

Regular, flexible and informal communication between the school and the project was critical to the strength of the partnership and the success of the project. Any problems could be identified and ironed out very early on. The strong involvement in and commitment to the project of the head teacher was also significant. When appropriate, 
project workers would also go and see participants' parents/carers if there were particular issues to discuss or else just to give general feedback about their child's progress. Again, the approach was informal and flexible.

Effectiveness. The Anti-Rust project appeared to achieve some notable successes. Without exception, all those interviewed from the project and the referring school felt that the success rate was very high.

Impact was described at a number of different levels. The head teacher from the referring school was unequivocal about the project's success in terms of participants' attendance, behaviour and performance at school:

Most [participants] have improved [in Maths and English]. There have been no failures in terms of misbehaviour or truanting.

Another area of impact was in raising participants' confidence and self-esteem. Learning new skills and achieving tangible outcomes (such as exhibiting produce at local gardening shows) helped participants to take more pride in themselves and their achievements. This was reflected in the relative lack of difficulty in maintaining project attendance levels. Most enjoyed coming and looked forward to it, a considerable achievement given that many of those referred had previously been truanting from school. Project workers also provided positive adult male role models and this was felt to be particularly important as a number of participants had little contact with their own fathers.

The project achieved some educational successes too. Participants learned horticultural skills, about the seasons and about the growing process. Some of these skills, and more generally the gaining of considerable work experience, also increased the participants' future employability. In addition, they learned about vegetables and healthy eating which for some was significant, as the head teacher from the referring school noted in interview:

Some don't know what vegetables are. The main meal's from the chip shop.

Produce was also taken home, leading potentially to a direct improvement in healthy eating for the young person and their family. Less directly, there were some opportunities for working on literacy problems, as participants were required to produce regular short reports. For those that found this difficult, project workers and volunteers would provide help.

The project also had a diversionary impact in terms of occupying participants' time constructively. Not only did it reduce levels of truanting and non-attendance at school, but it also kept some of the boys engaged in activities during school holidays, a time when they might otherwise seek employment on the markets in Salford and/or be prone to "recruitment" by older young people engaged in criminal activity. There is emerging research evidence that gardening and horticulture can be particularly effective as diversionary activities (Cammack et al., 2002; McGuinn and Relf, 2001).

More broadly, the project chair suggested in interview that there was a positive impact for some in terms of "citizenship". He observed that there was often a general improvement in behaviour, they responded better to discipline and they appreciated working so closely with adults. The project emphasised team working, with the boys looking after each other's plots if another was away. It gave them a significant amount of responsibility, treating them similarly to adult trainees. The project's regime also 
replicated the structure of working life, preparing participants for future employment, as well as reinforcing the kind of structure required for school attendance.

Another wider positive impact of the project referred to by the head teacher from the referring school concerned the way the project utilised older people in the community and linked them to young people:

It is about bringing young and old people together. It is a model that should be utilised and channelled much more, as there are a number of older people who have time to spare. The skills of a generation are not shared enough.

This inter-generational aspect was conceived as a significant dimension of the project, as reflected in its name, "Anti-Rust", which refers to the utilisation of older community members whose skills might otherwise go to waste. As Gillies (1997) has noted, this harnessing of the under-utilised "social capital" in local communities was one of the original intentions of the health action zones.

Overall, the Anti-Rust project appeared to be highly promising. The basic project model was innovative and theoretically sound, operating at a number of different levels, and was implemented well. Perceptions of impact were extremely positive. Lack of case monitoring or outcome data, however, precludes a more definitive assessment of project effectiveness.

\section{Discussion}

The two projects reported on here provide examples of innovative prevention work targeted at children disaffected from school. Some key issues for discussion have emerged from the research.

\section{Mentoring and matching}

Both of the projects incorporated a mentoring element. The evidence base for the preventative impact of mentoring for young people is still under-developed, with some positive US evidence (Tierney et al. 1995) but more mixed findings in the UK (Tarling et al., 2001; St James-Roberts and Singh, 2001). Both Kick It and Anti-Rust made distinctive use of mentors in that although they adopted the well-established "contract" mentoring model (a mature and experienced adult provides support and guidance and acts as a role model to a young person for a predefined period of time), they did not carry out any individual matching of mentors with mentees. The success of Anti-Rust, in particular, raises the question then of whether individual matching is important or not. There is some debate in the literature about this, with some suggesting that a degree of matching is essential (St James-Roberts and Singh, 2001) and others arguing that it is not (Sipe, 2002). On the basis of the two projects reported on here, there is evidence to support the view that for the majority of young people, the personal characteristics of the mentor are the key factor over and above, for example, gender or ethnicity. There is a parallel here, too, with current debates about "culturally competent" drug services. As Khan (2002, p. 11) argues:

The task is not to deliver a culturally appropriate service but an individually appropriate service that takes account of the full humanity of the client, including culture and heritage.

On this view, it is a false assumption that a shared skin colour or heritage or gender necessarily enables a mentor to deal more effectively with a young person. Nor is it 
clear why certain characteristics (typically "visible" ethnicity and gender) are privileged as important criteria for matching over and above others (such as, class, religion or education). The critical test then is whether mentoring is structured, organised and delivered so that effective relationships can be developed that are tailored to the needs of each individual.

\section{"Dosage"}

The term "dosage" refers to the amount of the intervention that is delivered to the young person. There was a vast difference in dosage between Kick It and Anti-Rust. Kick It participants actually only participated in a handful of sessions whereas those with Anti-Rust participated for three full days a week over the course of two academic years and, on top of this, had the opportunity to attend during school holidays.

The important question in terms of "dosage" is how much is enough? This is not just about effectiveness but also about cost and value-for-money. Kick It and Anti-Rust probably lie at opposite extremes of the spectrum on this point, with the dosage in the former clearly insufficient but the latter arguably too much. Interestingly, the evaluation of Project CHANCE questioned whether 40 meetings totalling 120 hours over the course of one year was "enough" (St James-Roberts and Singh, 2001, p. 40). This implies that the Anti-Rust model may be closer to the optimum "dosage" than Kick It. It seems likely too that required "dosage" will depend to quite a large extent on the individual and on the incidence of other life events during the intervention which threaten to throw that individual off course. Flexibility and tailoring to the needs of individuals will clearly be important. There is obviously a significant gap here in the evidence base where more research is needed.

\section{Vulnerable or difficult?}

For both projects it was clear that although they worked with vulnerable and disaffected young people, there were limits to who they could work with effectively. Children at the "harder" end in terms of behaviour and needs could not be accommodated within the structures of the two projects. For example, as described above, Kick It stopped taking referrals from pupil referral units as they could not be effectively engaged. This raises the question of how to develop and organise effective prevention for the most behaviourally challenging children. There are two likely answers to this. First, the intensity of supervision and support would need to be much higher to achieve successful engagement and retention. Whilst the short-term costs of this would be high, the potential longer-term savings could be enormous. Second, earlier intervention may be the key to preventative work with the most challenging children (Archer et al., 2002, p. 53). Project CHANCE is an example of an attempt to work with primary school children, although the evidence so far on its effectiveness is mixed (St James-Roberts and Singh, 2001).

\section{Evaluating multi-modal approaches}

It is a recurring theme in the prevention literature that multi-modal or multi-agency approaches that address multiple risk factors in a holistic way are the most effective (Archer et al., 2002, p. 52). The project models for both Kick It and Anti-Rust were clearly based on this idea. Evaluating multi-modal projects or programmes raises a major methodological and analytical difficulty of disentangling the relative importance 
of different components to achieving prevention outcomes. Understanding which components, alone or in combination, are the most critical to success is obviously essential for the replication of effective projects. Whilst there are no easy answers to this, it is argued that intensive qualitative enquiry focusing on understanding the linkages between contexts, mechanisms and outcomes offers the best way forward (Pawson and Tilley, 1997) and this was central to the approach adopted in this research. It is argued too that this provides a much more useful basis for the replication of success rather than approaches which look at replicating whole projects.

\section{Conclusion}

So what are the prospects for the future development of innovative prevention work with disaffected children of the kind reported on here? In policy terms, one of the difficulties that the projects faced was in securing sustainable funding. Anti-Rust, in particular, as it did not even have an explicit drugs focus, tended to fall between funding "stools". Some policy developments in the last few years suggest that there is now a more positive outlook for this kind of work. Firstly, drug action teams are now required to co-ordinate the production of young people's substance misuse plans (YPSMPs) with the involvement of other children's and young people's services in order to ensure a more integrated approach to meeting young people's substance misuse needs. Secondly, following the cross cutting review of children at risk for the 2002 comprehensive spending review, local authorities have been required to develop cross-cutting prevention plans for children and young people. This builds on the approach set in train by the YPSMPs and has the potential to cement the place of generic prevention work within prevention strategies and to ensure adequate funding for it from statutory agencies. The "silo" effect from which projects like Anti-Rust can suffer should, in principle at least, be largely avoided.

The recent green paper, Every Child Matters (Department for Education and Skills, 2003), further develops the integrated approach to provision for children and families. It seeks to enhance the quality of services by tightening up the accountability, consistency and co-ordination of provision. This poses, however, a real challenge for local authorities of how they can support small community-based projects of the kind reported on here so that real innovation that is genuinely rooted in communities can be fostered and nurtured. The danger is that this opportunity for innovation will be lost within the statutory planning frameworks.

\section{References}

Archer, D., Skinns, L. and Longstaff, E. (2002), Promising Prevention: A Review of Promising and Effective Approaches to Preventing Offending by Young People, Nacro, London.

Audit Commission (1996), Misspent Youth: Young People and Crime, Audit Commission, London.

Cammack, C., Waliczek, T.M. and Zajicek, J.M. (2002), "The green brigade: the psychological effects of a community-based horticultural program on the self-development characteristics of juvenile offenders", Horttechnology, Vol. 12 No. 1, pp. 82-6.

Department for Education and Skills (2003), Every Child Matters, The Stationery Office, London.

Flood-Page, C., Campbell, S., Harrington, V. and Miller, J. (2000), Youth Crime: Findings from the 1998/99 Youth Lifestyles Survey, Home Office Research Study 209, Home Office, London. 
Fraser, P. and Seddon, T. (2003), Drug Prevention for Vulnerable Young People: Issues for Planning, Evaluation and Practice, Research Briefing 3, Nacro, London.

Gillies, P. (1997), "Social capital: recognising the value of society”, Healthline, Vol. 45, pp. 15-17.

Glaser, B.G. and Strauss, A. (1967), The Discovery of Grounded Theory: Strategies for Qualitative Research, Aldine, Chicago, IL.

Goulden, C. and Sondhi, A. (2001), At the Margins: Drug Use by Vulnerable Young People in the 1998/99 Youth Lifestyles Survey, Home Office Research Findings 228, Home Office, London.

Graham, J. and Bowling, B. (1995), Young People and Crime, Home Office Research Study 145, Home Office, London.

Khan, K. (2002), “Culture before client: the wrong way for drug services”, Druglink, Vol. 17 No. 6 , pp. $10-12$.

Lloyd, C. (1998), "Risk factors for problem drug use: identifying vulnerable groups' drugs: education", Prevention and Policv, Vol. 5 No. 3, pp. 217-32.

McGuinn, C. and Relf, P.D. (2001), "A profile of juvenile offenders in a vocational horticulture curriculum”, Horttechnology, Vol. 11 No. 3, pp. 427-33.

MORI (2000), Youth Survey: Research Conducted for the Youth Justice Board, MORI, London.

Pawson, R. and Tilley, N. (1997), Realistic Evaluation, Sage, London.

Sipe, C.L. (2002), "Mentoring programmes for adolescents: a research summary", Lournal of Adolescent Health, Vol. 31, pp. 251-60.

Social Exclusion Unit (1998), Truancy and School Exclusion Report, The Stationery Office, London.

St James-Roberts, I. and Singh, C.S. (2001), Can Mentors Help Primary School Age Children with Behaviour Problems? Final Report of the Three-Year Evaluation of Project CHANCE Carried Out by the Thomas Coram Research Unit Between March 1997 and 2000, Home Office Research Study 233, Home Office, London.

Tarling, R., Burrows, J. and Clarke, A. (2001), Dalston Youth Project Part II (11-14): An Evaluation, Home Office Research Study 232, Home Office, London.

Tierney, J.P., Grossman, J.B. and Resch, N.L. (1995), Making a Difference: An Impact Study of Big Brothers/Big Sisters, Public/Private Ventures, Philadelphia, PA.

Townsend, P. (1998), Inequalities in Health: The Need to Construct More Comprehensive Health Policies, HEA Occasional Paper, HEA, London. 
This article has been cited by:

1. Eric MacIntosh, A. Lauren Couture, Kirsty Spence. 2015. Management challenges in delivering an international sport and development program. Sport, Business and Management: An International Journal 5:3, 276-296. [Abstract] [Full Text] [PDF]

2. Alan Sanders, Belinda Heys, Neil Ravenscroft, Daniel Burdsey. 2014. Making a difference: the power of football in the community. Soccer \& Society 15, 411-429. [CrossRef]

3. Sarah Davies, Miranda Thurston. 2005. Establishing a Learning Mentor Service within a Cluster of Primary Schools: Learning from Evaluation. Pastoral Care in Education 23:10.1111/past.2005.23.issue-3, 37-43. [CrossRef] 